\title{
The Impact of National Culture on Mobile Commerce Adoption and Usage Intensity
}

\author{
Timo Mandler \\ University of Hamburg \\ timo.mandler@uni-hamburg.de \\ Ingo Knuth \\ HMKW Berlin \\ i.knuth@hmkw.de
}

Rouven Seifert

University of Hamburg

rouven.seifert@,uni-hamburg.de

\author{
Christian-Mathias Wellbrock \\ University of Cologne \\ christian.wellbrock@uni-koeln.de
}

\author{
Reinhard Kunz \\ Management Center Innsbruck \\ reinhard.kunz@mci.edu
}

\begin{abstract}
The usage of mobile commerce increases around the world. However, little is known about why adoption and usage of mobile commerce services differ across countries. We address this question by analyzing the impact of national culture on mobile commerce adoption and usage intensity. Using a dataset that comprises individual consumer survey data from 43 countries across six continents and country-level data on Hofstede's six cultural dimensions, we study crosscultural adoption and usage patterns pertaining three mobile commerce services, i.e. mobile banking, mobile shopping and mobile payment. Our results show that adoption and usage intensity are indeed affected by different cultural dimensions. Specifically, the adoption of mobile commerce services is negatively influenced by a country's level of uncertainty avoidance, while consumers' usage intensity is driven by indulgence. This implies that providers of mobile commerce services need to tailor their market entry and market cultivation strategies accounting for each country's specific culture.
\end{abstract}

\section{Introduction}

With the proceeding diffusion of mobile devices, such as smartphones and tablet computers, the usage of so-called mobile commerce services is expected to intensify as well. We define a 'mobile commerce service' as any transaction with a monetary value that is conducted via a wireless telecommunication network [1] - [2]. Already today, major mobile commerce services, such as mobile banking, mobile payment and mobile shopping, are used by consumers in many countries around the world. As adoption and usage patterns of products and services in general are affected by the cultural and institutional context in which consumers live, cross-cultural differences in the consumers' use of mobile commerce services are likely to exist as well [3] - [4].

Understanding the role of culture in the context of mobile services is of great importance for both academic research and management practice. Particularly for managers, such insights could help service providers (e.g., application developers), hardware manufacturers (e.g., device developers), and advertisers (e.g., budgetallocating agencies) to optimize their marketing strategies and offerings to consumers' needs in various cultures and to estimate market potentials and success expectancies around the world. Despite the high managerial relevance, empirical research on consumers' actual usage behavior across countries is still scarce.

Against this background, the aim of our study is to investigate the role of culture in the context of the adoption and usage of mobile commerce services. More specifically, on the basis of Hofstede's cultural framework, we examine the relationships among different cultural dimensions and consumers' (1) adoption and (2) usage intensity of three major mobile commerce services, namely mobile banking, mobile payment and mobile shopping. Building on an extensive dataset involving 16,200 consumers from 43 countries across six continents, we present a hierarchical linear model that explains consumers' adoption and usage intensity from a cultural perspective.

Our results suggest that the adoption of mobile commerce is consistently driven by uncertainty avoidance across all three services, while this cultural dimension has no effect on usage intensity. The effect of cultural dimensions on usage intensity of mobile commerce is rather differentiated, as different cultural dimensions, depending on the mobile commerce service, turn out to have a significant impact.

The insights imply that service providers, hardware manufacturers, and advertisers should take into account cultural dimensions when customizing their offerings to local markets and defining market-entry strategies in 
order to anticipate and subsequently address cultural adoption barriers more adequately. In addition, our results indicate clear differences between the adoption and usage intensity of mobile commerce when it comes to the impact of culture. Therefore, business strategies should also accommodate the diffusion stage of mobile commerce services.

Our study contributes to existing literature in several ways. From a theoretical standpoint, we illuminate the relevance of culture in mobile commerce acceptance across numerous countries and several services. From a methodological standpoint, we apply a two-stage hierarchical modelling approach, which accounts for (a) the clustered nature of the observations (consumers within countries) and (b) a potential selection bias (adopters vs. non-adopters) between the two stages investigated. Finally, from a managerial perspective, we contribute to a clearer understanding of which cultural dimensions should be considered relevant by stakeholders in that field.

\section{Related Research}

In general, the adoption and usage of innovations differ from one individual to another. There is a considerable amount of studies specifically addressing the adoption and usage of mobile services [5] - [12]. However, explanations for existent differences in consumers' adoption and usage patterns across cultures are scant. Some researchers have investigated the influence of cultural factors on the individual level in a single country [13] - [15]. However, these studies do not address cross-cultural variance. Cross-national and intercultural research is scarce in this field, but has recently drawn some attention [3].

Cross-cultural research has been an important area in information systems research [16]. One reason for this is that it yields practical implications for providers of information technology and services. Additionally, cross-cultural research is a good way of addressing the generalizability of findings and thus helps to advance theory [3], [17]. Given the growth of m-commerce in today's global markets, we believe this topic deserves more attention.

There is initial evidence that - similarly to welldocumented cross-cultural differences in the context of traditional media and the Internet - there are intercultural differences in the adoption and usage of mobile commerce services as well [18]. At the same time, research suggests that usage of mobile commerce differs significantly from usage of online services (see Lin 2011: 252, for a summary of the mobile banking case [7]). Thus, we expect unique results for the field of mobile commerce services.
A review of existent studies in this particular field of research (see Table 1) reveals that only some of the relevant studies employ an established cultural framework to investigate the impact of culture on the adoption and/or usage of mobile commerce. Those that do, all employ the Hofstede framework. We follow the tradition of employing Hofstede's dimensions of national culture as a means to operationalize culture.

We also find that the vast majority of studies address consumer behavioral intentions as dependent variables, such as intention to use or the adoption intention. In our study, we use both consumers' (1) adoption and (2) usage intensity of mobile commerce services as dependent variables, which allows a direct comparison of these two behavioral constructs.

Another take-away from Table 1 is that existing cross-national comparative research in the field of mobile commerce adoption/usage is mostly based on two countries. Exceptions are Chung and Holdsworth [19] who include three countries, as well as Zhang et al. [18] who conduct a meta-analysis that includes studies with data from a total of 54 countries. However, their comparison is limited to two groups (Eastern versus Western culture). We expand existing research in this regard by analyzing a dataset that includes individual consumer data from 43 countries.

Regarding the focus on cultural differences, four out of nine studies displayed in Table 1 do not explicitly address cultural differences [20] - [23], but compare patterns of consumer behavior and/or behavioral intentions associated with mobile commerce between countries in a descriptive manner. Among those that do address cultural differences, some operationalize culture on an individual level. Chung and Holdsworth [19], for instance, conclude that the more collectivist a country is, the more the adoption intention depends on whether opinion leaders endorse a mobile service. They draw their results from survey data from Kazakhstan, Morocco and Singapore. Hung et al. [24] model Hofstede's five cultural dimensions as moderators between perceived ease of use as well as perceived usefulness and intention to use and find uncertainty avoidance, individualism and long-term orientation as the most influential ones. Their study focuses on Malaysia and Taiwan.

Other studies incorporate Hofstede's cultural dimensions as explanatory factors at the national level [25] - [26], [18]. Dai and Palvia [25] as well as Harris et al. [26] do not explicitly operationalize culture in their statistical analyses, but they attribute differences in consumer behavior between the two countries to cultural differences. Dai and Palvia [25], for instance, confirm the expectation that individuals from cultures with low uncertainty avoidance are more likely to embrace new mobile services. Harris et al. [26] attribute 
differences between the UK and Hong Kong in usage of and attitudes to mobile commerce services to the levels of collectivism and power distance. Zhang et al. [18], by contrast, conduct a meta-analysis in which they include results from 53 studies on mobile commerce adoption. They divide the countries considered into an Eastern and a Western culture group and find, among other things, that perceived risk, perceived enjoyment and perceived cost play a more important role in Eastern cultures, while perceived usefulness appears to be more important in Western cultures.
We address cultural differences at the national level for several reasons. First, including culture at the national level is of high practical relevance, because knowledge about cultural patterns in mobile commerce adoption and usage can serve as valuable proxies for service providers to improve decision-making, e.g. on market-entry strategies. We also integrate national level cultural values with individual level technology attitudes to isolate the effect of culture while controlling for individual traits.

Table 1. Cross-national studies in mobile commerce adoption and usage

\begin{tabular}{|l|l|l|l|l|}
\hline Study & $\begin{array}{l}\text { Dependent } \\
\text { Variable }\end{array}$ & $\begin{array}{l}\text { Cultural } \\
\text { Measure }\end{array}$ & $\begin{array}{l}\text { Level of } \\
\text { Operationalization }\end{array}$ & Countries \\
\hline Bina and Giaglis 2007 & $\begin{array}{l}\text { Value Perception } \\
\text { Intention to Use } \\
\text { Usage }\end{array}$ & - & - & $\begin{array}{l}\text { South Korea } \\
\text { Greece }\end{array}$ \\
\hline Chong et al. 2012 & Adoption Intention & - & - & $\begin{array}{l}\text { China } \\
\text { Malaysia }\end{array}$ \\
\hline Chung and Holdsworth 2012 & Adoption Intention & Hofstede & Individual & $\begin{array}{l}\text { Kazakhstan } \\
\text { Singapore }\end{array}$ \\
\hline Dai and Palvia 2008 & Intention to Use & $\begin{array}{l}\text { (differences } \\
\text { attributed to } \\
\text { Hofstede) }\end{array}$ & National & $\begin{array}{l}\text { China } \\
\text { USA }\end{array}$ \\
\hline Harris et al. 2005 & $\begin{array}{l}\text { Usage Frequency } \\
\text { Usefulness } \\
\text { Satisfaction } \\
\text { Expensiveness }\end{array}$ & $\begin{array}{l}\text { (differences } \\
\text { Hofstede) }\end{array}$ & National & $\begin{array}{l}\text { Hong Kong } \\
\text { UK }\end{array}$ \\
\hline Hung et al. 2010 & Intention to Use & Hofstede & Individual & $\begin{array}{l}\text { Malaysia } \\
\text { Taiwan }\end{array}$ \\
\hline Lee et al. 2002 & Satisfaction & - & $\begin{array}{l}\text { Japan } \\
\text { South Korea }\end{array}$ \\
\hline Shin et al. 2014 & Usage Intensity & - & $\begin{array}{l}\text { USA } \\
\text { South Korea }\end{array}$ \\
\hline Zhang et al. 2012 & $\begin{array}{l}\text { Intention to Use } \\
\text { Actual Use }\end{array}$ & East vs. West & National & 54 (Meta) \\
\hline
\end{tabular}

\section{Conceptual Framework}

We define the term 'culture' as a system of basic common values shared by people in a given society [27]. A 'value' is commonly understood as "a centrally held, enduring belief which guides actions and judgments across specific situations" [28], thereby acting as important determinant of an individual's behavior [29]. The prevailing values in a society further influence other, more visible manifestations of culture, such as rituals, heroes, and symbols [29] - [30].
We apply Hofstede's framework to operationalize culture at the national level. On the one hand, it has widely been criticized as being derived from outdated data and lacking generalizability due to its work-related context and theoretical weaknesses [31] - [32]. On the other hand, the Hofstede framework is considered the most robust and comprehensive (in terms of the number of national samples) among the available frameworks [33] - [34], which is reflected by its dominant application in international marketing and management studies [32], [34] - [35]. 
The Hofstede framework originally included four cultural dimensions (power distance, uncertainty avoidance, individualism vs. collectivism, masculinity vs. femininity) and was later expanded by the addition of a fifth (long term vs. short term orientation) and sixth dimension (indulgence vs. restraint). The dimensions are defined as follows [30], [36]:

- Power Distance: the extent to which less powerful members of a society accept and expect that power is distributed unequally.

- Uncertainty Avoidance: the extent to which people feel threatened by uncertainty and ambiguity and try to avoid these situations.

- Individualism (versus Collectivism): the extent to which people are looking after themselves and their immediate family only versus belonging to ingroups that look after them in exchange for loyalty.

- Masculinity (versus Femininity): dominant values in a masculine society are achievement and success; the dominant values in a feminine society are caring for others and quality of life.

- Long-Term Orientation (versus Short-Term Orientation): the extent to which a society exhibits a pragmatic future-oriented perspective rather than a conventional historic or short-term point of view.

- Indulgence (versus Restraint): relatively free gratification of basic and natural human desires related to enjoying life and having fun.

Apart from the effect of culture on consumers' adoption and usage of mobile commerce, our conceptual framework further comprises individual characteristics that are likely to affect consumers' adoption and usage patterns as well. From a general perspective, we consider socio-demographic characteristics as important predictors, because media consumption differs significantly across demographic groups. Further, from a technology-specific perspective, we include consumers' attitudes towards technology (i.e. their overall stance towards digital technologies) on the one hand, and usage-related factors that facilitate the use of mobile commerce (e.g., mobile Internet connection) on the other hand.

\section{Model \& Data}

Following the outlined structure of our conceptual framework, we investigate the relationships between two distinctive sets of predictors (country and consumer characteristics) and two outcome variables (mobile commerce adoption and usage intensity). To model these relationships adequately, we use a two-stage hierarchical linear model. The model involves two stages, because we explicitly distinguish between (1) the adoption (whether a consumer uses a particular mobile commerce service at all; binary dependent variable) and (2) the usage intensity (of actual users only; continuous dependent variable) as two separate behavioral aspects that may be driven by different variables. Furthermore, the nested structure of our data (i.e. consumers nested within countries) warrants a hierarchical model structure in order to obtain unbiased estimates [40]. The model is estimated for three different mobile commerce services (mobile shopping, mobile banking and mobile payment) using HLM 7.0 and the full maximum likelihood estimator.

Since we observe non-users and users at the first stage (adoption), but only actual users at the second stage (usage intensity), a sample selection bias may be prevalent. To account for this potential problem, we use a procedure that identifies sample selection biases proposed by Heckman [37]. The according diagnostics indeed indicate a selection bias for certain subsamples and services. To correct for this selection bias, we estimate the Mills ratios for every individual $i$ and service $k$ using the Heckman estimation (a tobit typetwo model) and include these ratios as independent variables into the equations at stage two.

To analyze the impact of cultural values on (1) mobile commerce adoption (MCAD) and (2) mobile commerce usage intensity (MCUI) we define the following equations at two levels for each service with the same set of independent variables:

Individual-level:

$$
\begin{aligned}
M_{C A D} / M C U I_{i j}= & \beta_{0 j}+\beta_{1 j} * A G E_{i j}+\beta_{2 j} \\
& * G E N D E R_{i j}+\beta_{3 j} * E D U C_{i j}+\beta_{4 j} \\
& * I N C O M E_{i j}+\beta_{5 j} * E M P L O Y_{i j} \\
& +\beta_{6 j} * I N T U S A G E_{i j}+\beta_{7 j} \\
& * \text { MOBDATA } A_{i j}+\beta_{8 j} \\
& * \text { WIFIHOME }_{i j}+\beta_{9 j} * T A_{A D V} i j \\
& +\beta_{10 j} * T A_{D I G I_{i j}}+\beta_{11 j} * T A_{F U N} \\
& +\beta_{12 j} * T A_{P R I V}\left[+\beta_{13 j} * \operatorname{MILLS}_{i j}\right] \\
& +r_{i j}
\end{aligned}
$$

Country-level:

$$
\begin{array}{rl}
\beta_{0 j}=\gamma_{00}+\gamma_{01} & * \text { POWER }_{j}+\gamma_{02} * \operatorname{UNCERT}_{j}+\gamma_{03} \\
& * \operatorname{INDCOL}_{j}+\gamma_{04} * \text { MASC }_{j}+\gamma_{05} \\
& * \text { LTSTO }_{j}+\gamma_{06} * \text { INDUL }_{j}+\gamma_{07} \\
& * \text { GDPCAP }_{j}+\gamma_{08} * \text { INTUSERS } \\
& +\gamma_{07} * \text { MOBSUB } \\
+u_{0 j} \\
\beta_{p j}=\gamma_{p 0}+u_{p j}, \text { for } p=1-12[13]
\end{array}
$$

where $i$ represents individuals and $j$ represents countries.

The individual-level variables AGE, GENDER, EDUC, INCOME, and EMPLOY capture sociodemographic characteristics of individual $i$, i.e. age, 
gender $(0=$ female, $1=$ male $)$, level of education income (both ordinal scales), and employment status $(0=$ not doing paid work, $1=$ employed in full or part time or selfemployed).

Further, we include four single item technology attitude-related measures: The variable TA ADV stands for the belief of being a technologically advanced user, TA_DIGI captures a user's affinity for digital solutions to problems, TA_FUN is a measure for an underlying hedonic motivation, and TA PRIV measures a user's concern for data privacy online (all 5point Likert-scales ranging from "strongly disagree" to "strongly agree").

Additional usage-related variables comprise INTUSAGE which reflects the Internet usage intensity of individual $i^{1}$, MOBDATA which captures whether this individual uses a mobile data connection (i.e., UMTS/3G or LTE/4G) or not, and WIFIHOME which stands for whether this individual has wireless Internet connection at home or not.

For the usage intensity model (MCUI) we further include MILLS (thus, the equation contains the additional parameter $\beta_{13 j}$ ), which is the individual, service-specific Mills ratios from the Heckman estimation [37]. The error terms for the individual and country level are $r i j$ and $u 0 j$, respectively.

The dependent variables MCAD and MCUI were drawn from these single item questions: How often do you purchase products/services online? How often do you use online banking? How often do you use mobile payment? ${ }^{1}$ Respondents who answered "never" were coded as non-adopters, all other respondents as adopters.

For our analysis, we use cross-sectional data that has a multilevel structure where individuals are nested within countries. Variables on the individual level data were collected by Google and TNS in 2014 [38] as part of the Connected Consumer Study (CCS) and contain information from 16,200 respondents from 43 countries across six continents. Target population was the total adult population in each country surveyed.

Samples in each country were aimed to be representative of the total population. Bases on common standards, people in the age of 16 and older were surveyed in all countries, except in Argentina, Mexico, Brazil, China, Russia where the minimum age was 18 and Japan where the minimum age was 20 years. The sample size was set at a minimum of $n=1,000$ in each country. The survey data was collected in all countries either via telephone (CATI) or face to face (CAPI/PAPI). The choice of the survey method

\footnotetext{
${ }^{1}$ Scale: 7 (Several times a day), 6 (Once a day), 5 (2-6 times a week), 4 (Once a week), 3 (2-3 times a month), 2 (Once a month), 1 (Less than once a month); 0 (Never, i.e. non-user)
}

depended on telephone penetration rates in each country. CATI was done via random digit dialing sampling with a mix of landline and mobile phone numbers (dual-frame approach). CAPI and PAPI comprised a door-to-door method [38].

The questionnaire was standardized by mostly using the same questions and items for all countries. The survey was administered in the local language for all countries and has been localized according to specific market structures and product offers. Data was weighted according to local Census data [38].

On the country level, we include the culture measures power distance (POWER), uncertainty avoidance (UNCERT), individualism vs. collectivism (INDCOL), masculinity vs. femininity (MASC), long term vs. short term orientation (LTSTO), and indulgence vs. restraint (INDUL). The data source is Hofstede et al. [30].

In addition, we control for other cross-national differences that may influence mobile device usage by including GDPCAP (gross domestic product per capita in current US\$) and MOBSUB (the number of mobile phone subscriptions in country $j$ ). The data for these controls is drawn from the World Bank [39].

\section{Results}

In Table 2 (adoption stage), we report odd-ratios and in Table 3 (usage stage) unstandardized regression coefficients. All estimated models - with the exception of "usage stage, mobile payment" - exhibit an excellent reliability.

\subsection{Adoption Stage}

With respect to the adoption of mobile commerce, cultural factors seem to have a rather systematic and consistent impact. Specifically, uncertainty avoidance (UNCERT) has a negative effect on the adoption probability of all three services, i.e. that the more members of a society seek to avoid situations of uncertainty and ambiguity, the lower is the probability that its members adopt mobile commerce. Masculinity only has a positive effect on mobile shopping, i.e. that members of a relatively masculine society are more likely to adopt mobile shopping.

The individual variables also exert quite systematic effects, which are mostly intuitive. From the sociodemographic variables, age is negatively related to the adoption of all three mobile commerce services, while the opposite is the case for income. Gender does not play 
a role in the adoption of mobile commerce. Education only affects the adoption probability of mobile banking and payment in the way that higher education levels lead to a higher adoption probability. The employment status has a significantly positive impact on all three mobile commerce services, which can be interpreted as individuals who are currently doing paid work adopt mobile commerce more frequently. The overall Internet usage intensity increases the likelihood of adopting mobile commerce services across all models and having Wi-Fi at home also has a positive effect on mobile commerce adoption. The same holds true for having a mobile data subscription (data plan).

The effect patterns of the attitudinal variables are consistent across all three models. Being a technologically adept consumer (as measured by TA_ADV and TA_DIGI) increases the probability of adoption, while a strong concern for data privacy decreases the former. Consumers' hedonic motivation is unrelated to the likelihood of adopting mobile commerce, which is probably due to the predominantly utilitarian nature of the services. Overall, most effects that were found in the analysis appear consistently across all mobile commerce services, indicating that mobile commerce services can be considered a homogenous group with respect to adoption patterns. From a cultural perspective, consumers from societies with high degrees in terms of uncertainty avoidance are less likely to adopt mobile commerce.

Table 2. Results from the adoption stage models Note: Parameters shown are odds ratios from the hierarchical Bernouilli model (logit link function); ${ }^{*} p<0.05 ;{ }^{* *} p<0.01 ;{ }^{* * *} p<0.001$

\begin{tabular}{|l|l|l|l|}
\hline Fixed Effect & Mobile Shopping & Mobile Banking & Mobile Payment \\
\hline Intercept & $0.1584^{*}$ & $0.1976^{*}$ & $0.1055^{*}$ \\
GDPCAP & $1.0080^{* *}$ & 1.0026 & 1.0062 \\
MOBSUB & $0.9939^{* *}$ & $0.9943^{*}$ & 0.9937 \\
\hline POWER & 0.9990 & 0.9985 & 1.0048 \\
UNCERT & $0.9933^{* *}$ & $0.9906^{* *}$ & $0.9911^{*}$ \\
INDCOL & 0.9960 & 1.0072 & 1.0127 \\
MASC & $1.0104^{* *}$ & 0.9975 & 1.0024 \\
LTSTO & 1.0036 & 1.0060 & 1.0021 \\
INDUL & 1.0033 & 1.0065 & 1.0034 \\
\hline AGE & $0.9807^{* *}$ & $0.9840^{* * *}$ & $0.9823^{* * *}$ \\
GENDER & 1.0842 & 0.9250 & 0.9491 \\
EDUC & 1.0804 & $1.1358^{*}$ & $1.1129 *$ \\
INCOME & $1.2471^{* * *}$ & $1.1714^{* * *}$ & $1.2035^{* * *}$ \\
EMPLOY & $1.2952^{* * *}$ & $1.3793^{* * *}$ & $1.2768^{* * *}$ \\
INTUSAGE & $1.2360^{* * *}$ & $1.2406^{* * *}$ & $1.1777^{* * *}$ \\
WIFIHOME & $1.3174^{* * *}$ & $1.4061^{* * *}$ & $1.2553^{* *}$ \\
MOBDATA & 1.1289 & $1.3418^{*}$ & $1.2658^{*}$ \\
TA_ADV & $1.1984^{* * *}$ & $1.2263^{* * *}$ & $1.2012^{* * *}$ \\
TA_FUN & 1.0325 & 0.9854 & 0.9697 \\
TA_DIGI & $1.1059^{* * *}$ & $1.1265^{* * *}$ & $1.1303^{* * *}$ \\
TA_PRIV & $0.9012^{* * *}$ & $0.9009^{* *}$ & $0.8853^{* * *}$ \\
\hline N & 13,358 & 13,342 & 13,341 \\
Reliability & 0.867 & 0.898 & 0.957 \\
Var ${ }$ & $0.1237^{* * *}$ & $0.1742^{* * *}$ & $0.5743^{* * *}$ \\
\hline
\end{tabular}

\subsection{Usage Stage}

The results from the usage stage reveal a more nuanced picture. While our model does not explain mobile payment usage intensity well, the results from the mobile shopping and mobile banking models are similar, yet not as consistent as in the adoption stage.

Concerning the cultural variables, masculinity has a positive effect on shopping and a negative effect on banking, while indulgence has a positive impact on both of these mobile commerce services. Consumers from individualistic societies use mobile banking more frequently, while this variable shows no effect on mobile shopping or mobile payment.

With respect to socio-demographics, older individuals and women reveal a lower usage intensity of mobile banking, while income shows a positive relationship with mobile banking usage. The 
employment status has a similar effect on usage intensity of mobile shopping and mobile banking as in the adoption stage model, with individuals who currently do not pursue a paid job using these services less frequently. Internet usage, having Wi-Fi at home and mobile data subscriptions all affect mobile banking usage positively, while Internet usage also has a positive effect on the other two mobile commerce services.
The effects of technology attitudes are quite consistent in the adoption model with the exception of the inferior mobile payment model. Being a technologically adept consumer (as measured by TA_ADV and TA_DIGI) increases usage intensity of mobile shopping and banking. In contrast, hedonic motivation (TA_FUN) and data privacy concerns (TA_PRIV) do not play a significant role at this stage.

Table 3. Results from the usage stage models

Note: Parameters shown are regression coefficients from the hierarchical regression model; ${ }^{*} p<0.05 ;{ }^{* *} p<0.01 ;{ }^{* * *} p<0.001 ;{ }^{1)}$ Estimation based on only 42 countries due to an insufficient number of cases/users in one country (Egypt).

\begin{tabular}{|l|l|l|l|}
\hline Fixed Effect & Mobile Shopping & Mobile Banking & Mobile Payment ${ }^{1)}$ \\
\hline Intercept & -1.864 & -2.0430 & 0.4816 \\
GDPCAP & 0.0020 & 0.0034 & -0.0016 \\
MOBSUB & -0.0081 & -0.0052 & 0.0011 \\
\hline POWER & -0.0080 & -0.0041 & 0.0043 \\
UNCERT & -0.0073 & -0.0005 & 0.0069 \\
INDCOL & -0.0087 & $0.0150^{* *}$ & 0.0055 \\
MASC & $0.0133^{*}$ & $-0.0076^{* *}$ & 0.0011 \\
LTSTO & 0.0060 & 0.0039 & -0.0028 \\
INDUL & $0.0088^{*}$ & $0.0106^{* *}$ & 0.0037 \\
\hline AGE & -0.0259 & $-0.0209^{* *}$ & 0.0009 \\
GENDER & 0.0481 & $-0.1501^{*}$ & -0.0256 \\
EDUC & 0.0982 & 0.0389 & -0.0451 \\
INCOME & 0.2431 & $0.1276^{*}$ & -0.0216 \\
EMPLOY & $0.4972^{*}$ & $0.6314^{* *}$ & 0.2086 \\
INTUSAGE & $0.5212^{* * *}$ & $0.5599^{* * *}$ & $0.3075^{*}$ \\
WIFIHOME & 0.4338 & $0.5602^{*}$ & 0.0133 \\
MOBDATA & -0.0185 & $0.3022^{*}$ & 0.0176 \\
TA_ADV & $0.2122^{*}$ & $0.1753^{* *}$ & 0.0119 \\
TA_FUN & -0.0249 & -0.0131 & -0.0029 \\
TA_DIGI & $0.1605^{*}$ & $0.1454^{*}$ & 0.0224 \\
TA_PRIV & -0.1377 & -0.0545 & 0.0332 \\
\hline MILLS & 2.1331 & $1.9705^{*}$ & -0.5551 \\
\hline N & 4946 & 5249 & 3919 \\
Reliability & 0.862 & 0.814 & 0.633 \\
Var & $0.1639^{* * *}$ & $0.1169^{* * *}$ & $0.0547^{* * *}$ \\
\hline
\end{tabular}

\section{Discussion}

\subsection{Effects of Consumer Characteristics}

The effects observed at the individual level are fairly consistent across services, but vary across stages (adoption vs. usage intensity). In the adoption stage, most of the individual variables - with the exception of gender and hedonic motivation - are related to the probability to adopt mobile commerce in ways that could be expected, which speaks in favor of the validity of our approach.

However, usage intensity is not explained by individual variables to the same extent. With the exception of mobile payment, the usage of mobile commerce services is mainly driven by technological advancedness, digital affinity, and the intensity of overall Internet usage. Content-wise these variables are all closely related, while significant effects of other characteristics such as hedonic motivation and privacy concerns disappear in comparison to the adoption stage.

\subsection{Effects of Cultural Dimensions}

Overall, our results suggest that consumers' adoption and usage of mobile commerce services indeed are influenced by different cultural dimensions, even when controlling for a wide range of individual characteristics. While uncertainty avoidance is a consistent predictor for the adoption of mobile 
commerce across all three services, masculinity and indulgence seem to be important drivers of usage intensity (at least for mobile shopping and banking).

For practitioners, this means that the introduction of new mobile commerce services has better prospects in societies with low uncertainty avoidance, such as Denmark, Sweden, the UK and Ireland. At the same time, market entry in countries with high uncertainty avoidance, such as Central and Eastern European as well as Latin American countries, Japan and South Korea should go along with marketing efforts aiming at reducing the perceived uncertainty that such a new service might entail.

The usage of established (already adopted) mobile commerce services, on the other hand, is unrelated to uncertainty avoidance. Here, marketers should pay attention to indulgence levels of societies, as mobile commerce is more frequently used in countries with high indulgence ratings, such as Anglo-American countries, but also Sweden and Denmark. In contrast, particularly Eastern European and Asian countries score low on the indulgence dimension.

Therefore, countries that score low in uncertainty avoidance and high in indulgence - such as Denmark, Sweden and the UK - provide good cultural environments for both mobile commerce service adoption as well as usage intensity, therefore representing promising target markets. The opposite is the case for Eastern European countries as well as South Korea, as those countries score relatively high in uncertainty avoidance and low in indulgence.

From a theoretical perspective, our results confirm the negative effect of uncertainty avoidance on adoption from previous research on technology adoption in general [16], [42] - [43], as well as research on mobile service adoption, such as Dai \& Palvia's [25] (although they do not address uncertainty avoidance directly but the related factor of innovativeness). This effect is frequently attributed to the fact that new IT is usually perceived as risky and uncertain. Consequently, individuals in countries with high uncertainty avoidance tend to be more careful about adopting IT [16].

Previous research also suggests effects of collectivism and power distance on adoption and usage of IT in general [16], and mobile services in particular (Su \& Adam) [26], [44]. Concerning collectivism, we find no robust relationship (only mobile banking usage appears to be influenced by collectivism) and therefore little support for this effect. This might be due to the fact that we analyze services that can be considered rather asynchronous and impersonal. Harris et al. [26] argue that high degrees of collectivism could imply that individuals have a greater desire for synchronous and personal communication rather than for asynchronous and impersonal communication. It might thus not be surprising that we find no consistent effect of collectivism.

Concerning power distance, some empirical evidence from general IT research points towards positive effects [45], while others find a negative relationship [43], [46]. We find no significant effect in our data, which might be caused by the inclusion of the indulgence dimension in our model (this dimension was added to the Hofstede framework after the publication of the aforementioned studies). Some argue that in cultures with high power distance, individuals could be more relaxed and fun-loving [26] and therefore more likely to adopt new technologies. Since we include indulgence in our model, it is not surprising that we find positive effects on usage of mobile shopping and banking in this dimension rather than in power distance.

\section{Conclusions, Limitations and Future Research}

In this article, we studied the relationship between certain cultural dimensions and consumers' adoption and usage intensity of three major mobile commerce services. The results indicate that both the adoption and usage intensity of mobile commerce are driven to a varying extent by different cultural dimensions.

From a theoretical standpoint, we advance existent knowledge in this field of research by illuminating the role of culture in mobile commerce usage not only across numerous countries, but also across several services. From a managerial perspective, our insights show that service providers, hardware manufacturers, and advertisers should take into account cultural dimensions when customizing their digital services and defining market-entry strategies to anticipate and subsequently address cultural adoption barriers more adequately.

In particular, mobile commerce services are less frequently adopted in countries with relatively high levels of uncertainty avoidance (cet. par.). This implies that the introduction of mobile commerce services should be accompanied by stronger efforts that alleviate the perceived negative effects of new technologies and services.

At the same time, cultural dimensions are less powerful in explaining usage intensity of mobile commerce services. This implies that uncertainty is less influential once users got into touch with mobile commerce services, emphasizing the importance of individual experience concerning perceived uncertainty.

The only consistent effect of a cultural dimension we find at this latter stage is indulgence: the higher a country scores in indulgence, the more frequently consumers use mobile commerce services in this 
country. Since Denmark, Sweden and the UK score low in uncertainty avoidance and high in indulgence, these countries appear to be promising target markets.

We also find rather strong positive effects of control variables, in particular of individual characteristics such as income, employment, Internet usage, and technological advancedness. This can serve as an explanation as to why certain countries with high uncertainty avoidance still exhibit high adoption rates.

In this regard, it is noticeable in our view that national cultural values still exhibit a statistically significant effect on mobile commerce adoption and usage, even when controlling for individual traits.

Our research has several limitations that offer avenues for further research. First, we use multilevel data with country-level cultural dimensions. As we relied on secondary data drawn from the Connected Consumer Study provided by TNS and Google [38], we were not able to additionally capture cultural values at the individual level. An investigation as to whether the observed effects are coherent at the individual level, and how national cultural values interplay with personal cultural values, would be an interesting avenue for further research. This includes cultural variation between groups within countries.

Second, our analysis is limited to cross-sectional user data. An examination of the dynamics of adoption and usage patterns over time would allow a more precise understanding of the diffusion process and product lifecycle of mobile commerce across cultures.

Third, our study focuses on the effects of cultural dimensions and - due to the fact that we had to rely on secondary data - involves only two sets of technologyrelated predictors of adoption and usage behavior. We believe that further research could benefit from examining other individual-level predictors (e.g., lifestyle-related measures) to further explain more variance and provide managers a better tool for segmentation purposes. Due to our reliance on an external data source, we were also unable to include control variables from established technology acceptance models (such as TAM or UTAUT).

Finally, while mobile commerce appears to be a rather homogenous group of services with regard to consumer behavior patterns, it would be interesting to investigate differences between mobile commerce and other mobile services that serve different purposes. Although we found hedonic motivation to be without any considerable effect on mobile commerce adoption and usage intensity, a hedonic consumption motivation might play a pivotal role for other mobile services, such as mobile gaming or video services.

\section{References}

[1] Barnes, S. J. (2002) "The mobile commerce value chain: analysis and future developments." International Journal of Information Management 22 (2), 91-108.

[2] Wu, J. H. and S. C. Wang (2005). "What Drives Mobile Commerce?: An Empirical Evaluation of the Revised Technology Acceptance Model." Information \& Management 42 (5), 719-729.

[3] Hoehle, H., Zhang, X. and V. Venkatesh (2015) "An Espoused Cultural Perspective to Understand Continued Intention to Use Mobile Applications: A Four-Country Study of Mobile Social Media Application Usability." European Journal of Information Systems 24 (3), 337359.

[4] Kim, K. H., Ko, E., Takahashi, I., Schellhase, R., Kim, M. S. and C. H. Lee (2008) "A Model of Adoption of Digital Multimedia Broadcasting (DMB) Service: Comparisons in Korea, Japan, and Germany." Psychology \& Marketing 25 (8), 806-820.

[5] Gu, J. C., Lee, S. C. and Y. H. Suh (2009) "Determinants of Behavioral Intention to Mobile Banking." Expert Systems with Applications 36 (9), 11605-11616.

[6] Kim, C., Mirusmonov, M. and I. Lee (2010) “An Empirical Examination of Factors Influencing the Intention to Use Mobile Payment." Computers in Human Behavior 26 (3), 310-322.

[7] Lin, H. F. (2011) "An Empirical Investigation of Mobile Banking Adoption: The Effect of Innovation Attributes and Knowledge-Based Trust.” International Journal of Information Management 31 (3), 252-260.

[8] Luarn, P. and H. H. Lin (2005) "Toward an Understanding of the Behavioral Intention to Use Mobile Banking." Computers in Human Behavior 21 (6), 873-891.

[9] Luo, X., Li, H., Zhang, J. and J. P. Shim (2010) "Examining Multi-Dimensional Trust and MultiFaceted Risk in Initial Acceptance of Emerging Technologies: An Empirical Study of Mobile Banking Services." Decision Support Systems 49 (2), 222-234.

[10] Ovčjak, B., Heričko, M. and G. Polančič (2015) "Factors Impacting the Acceptance of Mobile Data Services-A Systematic Literature Review." Computers in Human Behavior (53), 24-47.

[11] Schierz, P. G., Schilke, O. and B. W. Wirtz (2010). "Understanding Consumer Acceptance of Mobile Payment Services: An Empirical Analysis," Electronic Commerce Research and Applications 9 (3), 209-216.

[12] Zhou, T., Lu, Y. and B. Wang (2010) "Integrating TTF and UTAUT to Explain Mobile Banking User Adoption." Computers in Human Behavior 26 (4), 760767.

[13] Baptista, G. and T. Oliveira (2015). "Understanding Mobile Banking: The Unified Theory of Acceptance and Use of Technology Combined with Cultural Moderators." Computers in Human Behavior (50), 418430.

[14] Faqih, K. M. and M. I. R. M. Jaradat (2015) "Assessing the Moderating Effect of Gender Differences and Individualism-Collectivism at Individual-Level on the Adoption of Mobile Commerce Technology: TAM3 
Perspective." Journal of Retailing and Consumer Services (22), 37-52.

[15] Min, Q., Li, Y. and S. Ji (2009) "The Effects of Individual-Level Culture on Mobile Commerce Adoption: An Empirical Study" In: Proceedings of the 8th International Conference on Mobile Business, 305312.

[16] Leidner, D. E. and T. Kayworth (2006) "A review of culture in information systems research: toward a theory of information technology culture conflict." MIS quarterly 30 (2), 357-399.

[17] Lee, A. S. and R. L. Baskerville (2003) "Generalizing generalizability in information systems research." Information Systems Research 14 (3), 221-243.

[18] Zhang, L., Zhu, J. and Q. Liu (2012) “A Meta-Analysis of Mobile Commerce Adoption and the Moderating Effect of Culture." Computers in Human Behavior 28 (5), 1902-1911.

[19] Chung, K. C. and D. K. Holdsworth (2012) "Culture and Behavioural Intent to Adopt Mobile Commerce Among the Y Generation: Comparative Analyses Between Kazakhstan, Morocco and Singapore." Young Consumers 13 (3), 224-241.

[20] Bina, M. and G. M. Giaglis (2007). "Perceived Value and Usage Patterns of Mobile Data Services: A CrossCultural Study." Electronic Markets 17 (4), 241-252.

[21] Chong, A. Y. L., Chan, F. T. and K. B. Ooi (2012). "Predicting Consumer Decisions to Adopt Mobile Commerce: Cross Country Empirical Examination between China and Malaysia." Decision Support Systems 53 (1), 34-43.

[22] Lee, Y., Lee, I., Kim, J. and H. Kim (2002) "A CrossCultural Study on the Value Structure of Mobile Internet Usage: Comparison between Korea and Japan." Journal of Electronic Commerce Research 3 (4), 227-239.

[23] Shin, S., Lee, W. J. and D. O. Odom (2014). "A Comparative Study Of Smartphone User's Perception and Preference Towards Mobile Payment Methods in the US And Korea." Journal of Applied Business Research 30 (5), 1365-1376.

[24] Hung, C. L., Chou, J. C. L., Chung, R. Y. and T. P. Dong (2010). "A Cross-Cultural Study on the Mobile Commerce Acceptance Model." 2010 International Conference on Management of Innovation and Technology, 462-467.

[25] Dai, H., and P. Palvia (2008) "Factors Affecting Mobile Commerce Adoption: A Cross-Cultural Study in China and the United States." In: Proceedings of the 2008 Americas Conference on Information Systems (Paper 204), 1-14.

[26] Harris, P., Rettie, R. and C. K. Cheung (2005) “Adoption and Usage of M-Commerce: A Cross-Cultural Comparison of Hong Kong and the United Kingdom." Journal of Electronic Commerce Research 6 (3), 210224.

[27] Granato, J., Inglehart, R. and D. Leblang (1996) "The Effect of Cultural Values on Economic Development: Theory, Hypotheses, and Some Empirical Tests." American Journal of Political Science 40 (3), 607-631.
[28] Rokeach, M. 1968. Beliefs, Attitudes, and Values: A Theory of Organization and Change. San Francisco: Jossey-Bass.

[29] Luna, D. and S. F. Gupta (2001) "An Integrative Framework for Cross-Cultural Consumer Behavior." International Marketing Review 18 (1), 45-69.

[30] Hofstede, G., Hofstede, G. J. and M. Minkov (2010). Cultures and Organizations: Software of the Mind. $3^{\text {rd }}$ Edition. New York: McGraw-Hill.

[31] Ng, S. I., Lee, J. A. and G. N. Soutar (2007) "Are Hofstede's and Schwartz's Value Frameworks Congruent?" International Marketing Review 24(2), 164-180.

[32] Steenkamp, J.-B. E. M. (2001). "The Role of National Culture in International Marketing Research.” International Marketing Review 18 (1), 30-44.

[33] Smith, P., Dugan, S. and F. Trompenaars (1996). "National culture and the values of organizational employees - a dimensional analysis across 43 nations." Journal of Cross-Cultural Psychology 27 (2), 231-64.

[34] Soares, A. M., Farhangmehr, M. and A. Shoham (2007) "Hofstede's dimensions of culture in international marketing studies." Journal of Business Research 60 (3), 277-284.

[35] Sondergaard, M. (1994). "Research note: Hofstede's consequences: a study of reviews, citations and replications." Organization Studies 15 (3), 447-56.

[36] De Mooij, M. and G. Hofstede (2011) "Cross-Cultural Consumer Behavior: A Review of Research Findings." Journal of International Consumer Marketing 23 (3-4), 181-192.

[37] Heckman, J. J. (1979) "Sample Selection Bias as a Specification Error." Econometrica 47 (1), 152-161.

[38] TNS and Google. (2016). Connected Consumer Study. URL: https://www.consumerbarometer.com/en/about. (visited on 10/14/2016)

[39] World Bank 2014. World Bank Open Data. URL: http://data.worldbank.org/. (visited on 09/19/2015)

[40] Aitkin, M., Anderson, D. and J. Hinde (1981). "Statistical Modeling of Teaching Styles." Journal of the Royal Statistical Society Series A 144 (4), 419-461.

[41] Raudenbush, S. W. and A. S. Bryk (2002). Hierarchical Linear Models: Applications and Data Analysis Methods. Newbury Park: Sage.

[42] Hofstede, G. (1991). Culture and Organizations: Software of the Mind. London: McGraw Hill.

[43] Erumban, A. A. and S. B. De Jong (2006) "Cross-country differences in ICT adoption: A consequence of Culture?" Journal of world business 41(4), 302-314.

[44] Su, Q., and C. Adam (2004) "Differences in mobile adoption and use between China and the West (UK): Implications for future M-commerce development.” In: Proceedings of the Eighth Pacific Asia Conference of Information Systems, 2328-2334.

[45] DeVreede, G., Jones, N. and R. J. Mgaya (1998). "Exploring the Application and Acceptance of Group Support Systems in Africa." Journal of Management Information Systems 15 (3), 197-234.

[46] Hasan, H. and G. Ditsa (1999) "The Impact of Culture on the Adoption of IT: An Interpretive Study." Journal of Global Information Management 7 (1), 5-15. 